\title{
Secondary phimosis after circumcision
}

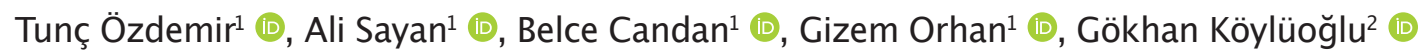

Cite this article as: Özdemir T, Sayan A, Candan B, Orhan G, Köylüoğlu G. Secondary phimosis after circumcision. Turk J Urol 2019; 45(2): 135-8.

ORCID IDs of the authors: T.Ö. 0000-0001-6800-2617; A.S. $0000-0002-1866-8899$; B.C. $0000-0002-4713-4255$; G.0. $0000-0002-5818-3925$; G.K. $0000-0002-1140-169 \mathrm{X}$

${ }^{1}$ Department of Pediatric Surgery, University of Medical Sciences, Tepecik Training and Research Hospital, İzmir, Turkey

${ }^{2}$ Department of Pediatric Surgery, Katip Çelebi University Tepecik Training and Research Hospital, İzmir, Turkey

Submitted:

24.01.2018

Accepted:

13.09.2018

Available Online Date: 22.01.2019

Corresponding Author: Tunç Özdemir

E-mail:

ozdemirtunc@yahoo.com

(C) Copyright 2019 by Turkish

Association of Urology

Available online at

www.turkishjournalofurology.com

\section{ABSTRACT}

Objective: Male circumcision is one of the most common surgical procedures worldwide. Although it is widely performed because of health issues, in Muslim-majority countries, the primary motivation yielding to male circumcision is religious. It is a relatively safe procedure with a low overall complication rate. We herein report an underrated complication of circumcision that can be termed as "secondary phimosis."

Material and methods: The medical records of 25 boys with post-circumcision secondary phimosis were reviewed. Demographics of the patients, method of circumcision, type of provider, peroperative findings and comorbidities were recorded.

Results: Between January 2005 and December 2016, 25 boys with post-circumcision secondary phimosis were treated surgically. The median age of the patients was 3 (2-5) years. The majority of the patients were circumcised by the Gomco clamp or Plastibell method $(n=16)$. Of the patients' circumcisions, six were performed by the freehand method, and three by the dorsal slit method. In 15 boys, circumcision was performed by a traditional provider. Of the boys, seven were circumcised by a physician, and three were circumcised by a pediatric surgeon. All the patients were re-circumcised. The common peroperative finding was the redundant mucosal inner layer of the prepucium. Excess suprapubic fat was present in 12 patients.

Conclusion: Although circumcision is known as a minor surgical practice with low complication rate, it must be performed safely and especially by experienced physicians/surgeons. Secondary phimosis is a technical error that is caused by insufficient removal of the inner mucosal layer of the prepucium. Re-circumcision of the patient is inevitable, causing the patient second trauma.

Keywords: Circumcision; complication; phimosis.

\section{Introduction}

Circumcision is one of the most common surgical operations in neonates, infants, and children for cultural, religious, and medical reasons..$^{[1,2]}$ However, there are insufficient data about the safety and complications of this procedure. Several techniques exist to remove the prepucium. The most common techniques are Plastibell, Gomco clamp, and Mogen clamp techniques that involved devices and surgical techniques, such as freehand technique and dorsal slit technique. ${ }^{[3]}$ Other than local edema and pain, bleeding and inadequate skin removal are the early complications of circumcision. ${ }^{[3]}$ Iatrogenic chordee, iatrogenic hypospadias, glanular necrosis, and glanular amputation are serious early complications. ${ }^{[3]}$ Late complications include epidermal inclusion cysts mostly related to retaining suture material, suture sinus tracts, chordee, inadequate skin removal resulting in redundant foreskin, penile adhesions, phimosis, buried penis, urethrocutaneous fistulae, meatitis, and meatal stenosis. ${ }^{[3]}$ Some of these complications require subsequent surgical intervention.

The aim of the present study was to define this rare complication in terms of cause, findings, presentation, and treatment strategies. Technical error yielding to secondary phimosis was also discussed.

\section{Material and methods}

The present study was performed in accordance with the Declaration of Helsinki of the World Medical Association. All parents signed and understood the informed consent forms regarding the procedures. All male patients were referred or admitted to our clinic for treatment 
of secondary phimosis after circumcision. Eligibility criteria were total stricture of the circumcision line and inability of retraction of penile skin. A total of 25 boys who were circumcised elsewhere were included in the study. All patients were aged 2-5 (median 3) years. Data collection involved a structured questionnaire administered by a trained research assistant. Data collected included demographic information, person circumcising, age at circumcision, place of circumcision, physical examination findings, and peroperative observations. Data were collected over a 20-month period from January 2005 to December 2016.

\section{Table 1. Complications according to providers}

\begin{tabular}{lccc} 
Providers & Gomco-Plastibell & Freehand & Dorsal slit \\
\hline Traditional & 11 & 4 & 0 \\
Physician & 4 & 2 & 1 \\
\hline Pediatric surgeon & 1 & 0 & 2
\end{tabular}

\section{Statistical analysis}

The data were analyzed by using Statistical Packages for the Social Sciences (SPSS Inc.; Chicago, IL, USA) for Windows version 16 .

\section{Results}

A total of 25 cases of children with post-circumcision secondary phimosis were seen during the 11-year period. The youngest boy was a 2-year-old patient, and the oldest was an 11-year-old patient. The latest onset of the patients was 3 years in one boy, and the earliest onset was 2 months in one. The method of circumcision used was Gomco or Plastibell clamp in the majority of the patients ( $\mathrm{n}=16,64 \%$; Table 1$)$. Six patients were circumcised by the freehand method (24\%), and three patients were circumcised by the dorsal slit method (12\%). Circumcisions were performed by traditional circumcizers in 15 patients, physicians in seven patients, and pediatric surgeons in three patients (Table

Table 2. Circumcision methods, anatomical details, and providers of the patients

\begin{tabular}{|c|c|c|c|c|c|}
\hline No. & Age (years) & Age at circumcision (years) & Method & Anatomical detail & Provider \\
\hline 1 & 4 & 3 & Gomco & Buried & Traditional \\
\hline 2 & 3 & 3 & Freehand & Suprapubic fat & Traditional \\
\hline 3 & 2 & 1 & Dorsal slit & Suprapubic fat & Pediatric surgeon \\
\hline 4 & 5 & 4 & Gomco & & Traditional \\
\hline 5 & 4 & 4 & Plastibell & & Traditional \\
\hline 6 & 2 & 1 & Gomco & Suprapubic fat & Traditional \\
\hline 7 & 5 & 4 & Gomco & & Physician \\
\hline 8 & 3 & 2 & Dorsal slit & Suprapubic fat & Physician \\
\hline 9 & 2 & 2 & Plastibell & Suprapubic fat & Traditional \\
\hline 10 & 3 & 3 & Plastibell & Suprapubic fat & Traditional \\
\hline 11 & 4 & 3 & Gomco & & Pediatric surgeon \\
\hline 12 & 2 & 2 & Freehand & Buried & Traditional \\
\hline 13 & 4 & 1 & Gomco & & Physician \\
\hline 14 & 3 & 2 & Plastibell & Suprapubic fat & Traditional \\
\hline 15 & 3 & 2 & Dorsal slit & & Pediatric surgeon \\
\hline 16 & 4 & 3 & Freehand & & Traditional \\
\hline 17 & 2 & 1 & Gomco & Suprapubic fat & Traditional \\
\hline 18 & 2 & 2 & Freehand & & Physician \\
\hline 19 & 5 & 4 & Gomco & & Traditional \\
\hline 20 & 3 & 2 & Plastibell & Suprapubic fat & Traditional \\
\hline 21 & 4 & 3 & Freehand & Buried & Physician \\
\hline 22 & 2 & 2 & Gomco & Suprapubic fat & Traditional \\
\hline 23 & 4 & 3 & Freehand & & Traditional \\
\hline 24 & 3 & 2 & Plastibell & & Physician \\
\hline 25 & 2 & 2 & Gomco & Suprapubic fat & Physician \\
\hline
\end{tabular}


1). Gomco-Plastibell clamp was the most commonly preferred method by traditional providers (44\%; Table 2 ).

During physical examination, it was observed that the glans penis was obscured by a strictured circumcision line in all the patients. Reduction of the skin surrounding the glans was impossible (Figures 1-3). All the patients were experiencing difficulties during voiding. Two patients had urinary tract infection. Prominent suprapubic fat was detected in $11(44 \%)$ patients. Three patients had a buried penis (1.2\%).

All the patients were operated. A strictured circumcision line was opened by limited dorsal slit. The common observation was excessive redundant inner mucosal layer of the prepucium in all patients. The inner mucosal layer was trimmed by scissors leaving a margin around the corona of approximately $3 \mathrm{~mm}$ circumferentially. Fibrotic skin was also excised from the outer skin layer of the prepucium. Re-circumcision was completed by

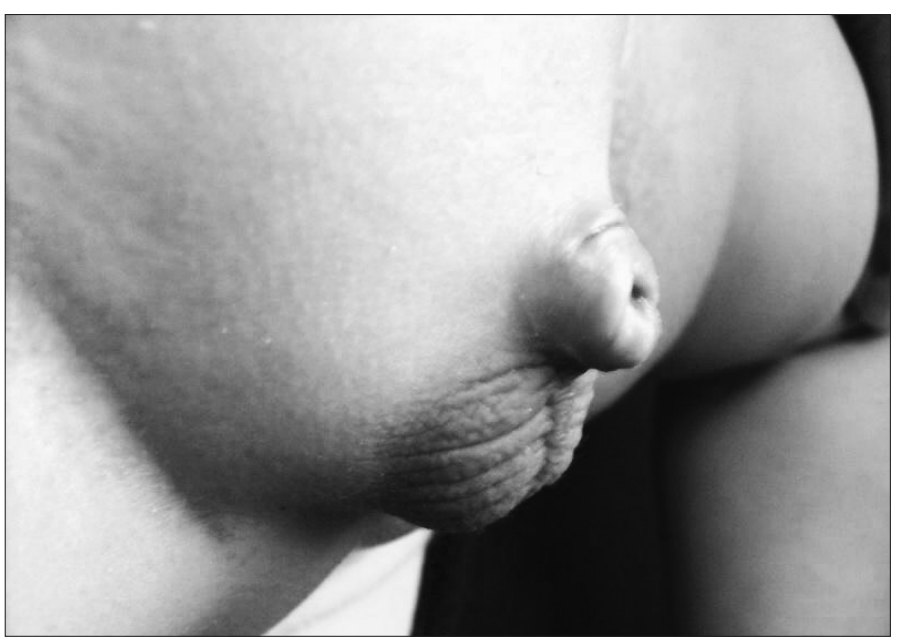

Figure 1. Secondary phimosis with buried penis

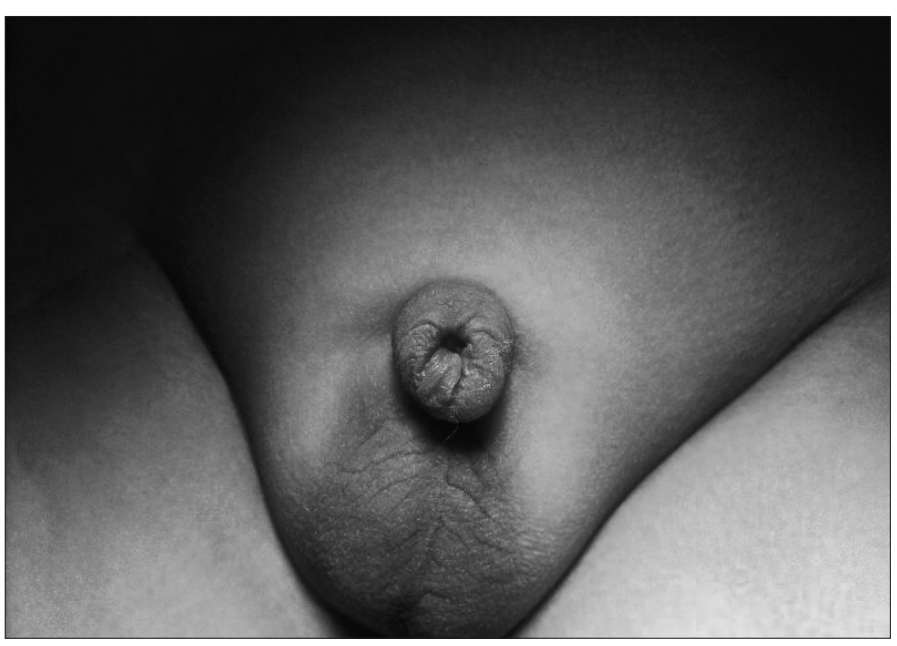

Figure 2. Secondary phimosis with excessive pubic fat interrupted absorbable sutures. Postoperative course of the patients was uneventful.

\section{Discussion}

Circumcision of boys is commonly practiced and will continue to occur for several reasons. Mostly, complications are minor and easily treatable, especially at young ages, but high frequency of complications, and severe complications, is observed when the procedure is performed by inexperienced providers, in non-sterile settings or with inadequate equipment and supplies. Boys undergoing circumcisions in medical facilities in developed countries performed by trained practitioners have fewer complications than boys in undeveloped areas who have circumcisions performed by poorly trained (or untrained) practitioners in nonmedical surroundings. ${ }^{[4]}$

The rate of unwanted events varies widely across reports, depending on the definition chosen for a postoperative complication. Complications may be minor and easily treatable, such as pain, bleeding, inadequate skin removal, and surgical site infection. ${ }^{[3]}$ Serious complications may occur, such as hypospadias, chordee, iatrogenic glanular necrosis, and glanular amputation. ${ }^{[3]}$ Epider-

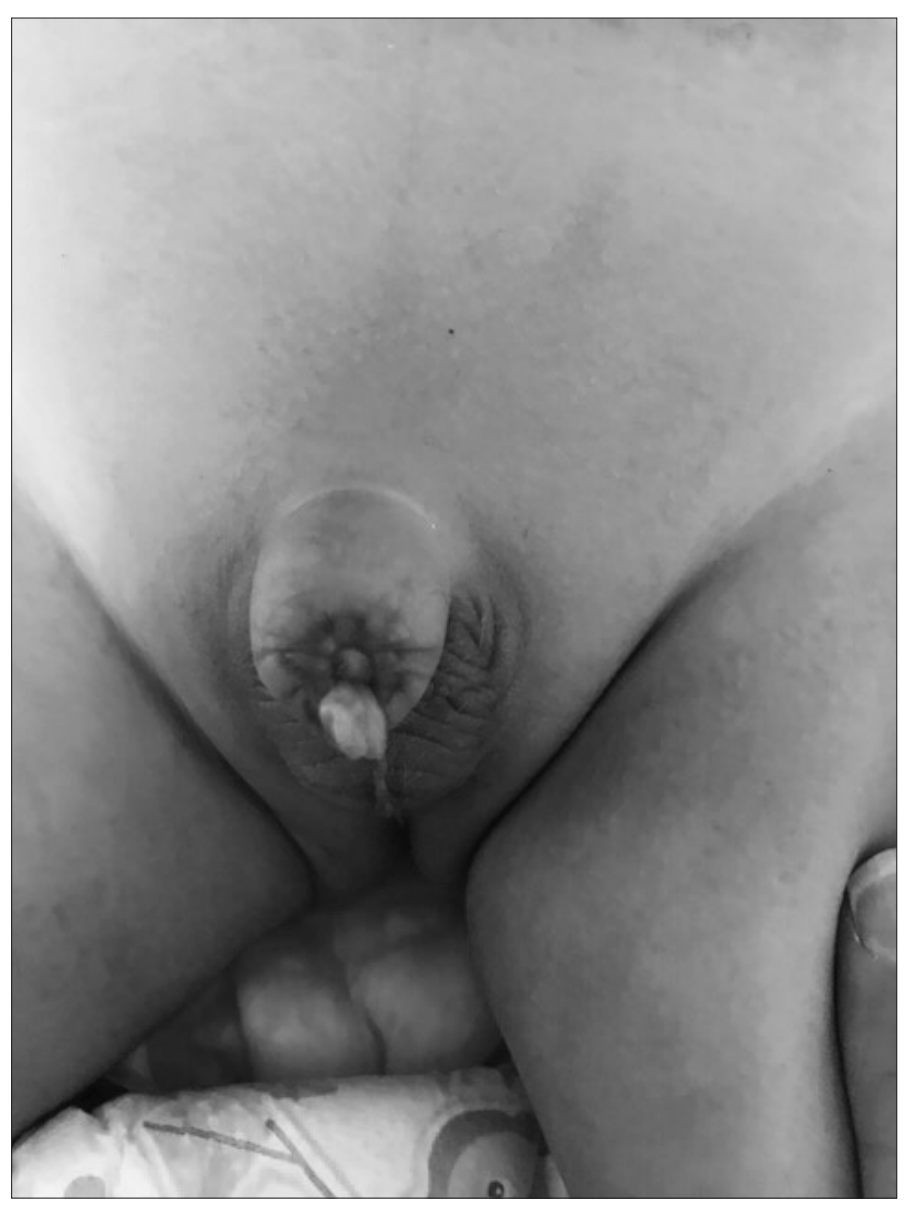

Figure 3. Secondary phimosis without additional pathology 
mal inclusion cysts, suture sinus tracts, chordee, inadequate skin removal resulting in redundant foreskin, phimosis, penile adhesions, buried penis, urethrocutaneous fistulae, meatitis, and meatal stenosis are the possible late complications that may occur. ${ }^{[3]}$

Secondary or acquired phimosis is mainly described as a complication of the Plastibell technique. ${ }^{[5]}$ Kidger et al.$^{[5]}$ defined the pathogenesis of this phenomenon as loose ligature or a smallersized Plastibell, leading to slippage of the inner layer of the skin. ${ }^{[5]}$ They stated that the outer layer cicatrizes gradually and results in a phimotic scar within 3 weeks..$^{[5]}$

The term trapped/concealed penis is also used to determine secondary phimosis from progressive closure and stricture of the skin over the glans penis. ${ }^{[3]}$ It is concluded that the cause of this phenomenon is excessive removal of the shaft skin coupled with a prominent suprapubic fat pad resulting in healing within the fat pad. ${ }^{[3]}$

During corrective surgery of patients with secondary phimosis, the common peroperative finding is excessive redundant inner mucosal layer of the prepucium. The suture line appose both edges of the prepucium was cicatrized/strictured and resulted in a phimotic scar. After removal of the cicatrix, trimming of the redundant inner layer of the prepucium was mandatory.

Although the Plastibell/Gomco technique appears as an effective tool for religious and cultural circumcisions in the community, especially in patients with prominent suprapubic fat, misalignment of the prepucium during setting the clamp yields to the redundant inner layer of the prepucium and subsequent secondary phimosis due to stricture of the suture line above the glans penis.

Similarly, even in experienced hands, freehand circumcision may yield to secondary phimosis if the inner layer of the prepucium was not trimmed subsequently.

Two patients were circumcised by the dorsal slit technique in our patient group. Excessive redundant inner mucosal layer of the prepucium was also detected in these patients. This unwanted result will be avoided by firmly compressing the fat pad to the abdominal wall to best determine how much skin should be removed. ${ }^{[3]}$

Patients with secondary phimosis are mainly presented with voiding difficulties and urinary infections. Owing to the coverage of the glans by penile skin, especially in patients with buried penis, iatrogenic amputation of the glans may be considered at first sight. Meticulous examination of the patients may yield the physician to correct diagnosis. In patients with voiding difficulties, dilation of the narrowed opening of the skin must be the first treatment of choice. In patients with buried penis, the remaining penile skin may be inadequate despite the redundant inner mucosal layer. In these subsets of patients, additional reconstructive efforts may be necessary.

To our knowledge, our patient group was the largest series with secondary phimosis in the English literature so far. There are limitations to our study. Despite the tertiary setting of our center, the actual frequency of secondary phimosis cannot be stated precisely. Moreover, retrospective analysis of data is another limitation.

Although surgical correction is possible, the first effort should be the avoidance of this complication. According to experience gained from this group of patients, especially in patients with prominent suprapubic fat, placement of Plastibell/Gomco clamp must be performed very carefully to avoid misalignment of the prepucium. During surgical circumcisions, the inner layer of the prepucium must be trimmed leaving a margin around the corona of a maximum of $3 \mathrm{~mm}$. The redundant inner layer of the prepucium causes stricture of the suture line appose both edges of the prepucium and secondary phimosis after circumcision, especially in patients with prominent suprapubic fat. The suprapubic fat should be compressed regularly after the procedure to allow the penis to be protruded. Corrective surgery may be necessary if there is absence or significant laxity of the penoscrotal angle or penoscrotal webbing that precludes adequate protrusion of the penis. ${ }^{[3]}$

Ethics Committee Approval: Authors declared that the research was conducted according to the principles of the World Medical Association Declaration of Helsinki "Ethical Principles for Medical Research Involving Human Subjects”, (amended in October 2013).

Informed Consent: Written informed consent was obtained all parents who participated in this study.

Peer-review: Externally peer-reviewed.

Author Contributions: Concept - T.Ö.; Design - T.Ö., A.S.; Supervision - T.Ö., G.K.; Resources - B.C., G.O.; Materials - T.Ö.; Data Collection and/or Processing - B.C., G.O.; Analysis and/or Interpretation - T.Ö., A.S., G.K.; Literature Search - T.Ö., A.S.; Writing Manuscript - T.Ö.; Critical Review - T.Ö., G.K.; Other - T.Ö.

Conflict of Interest: The authors have no conflicts of interest to declare.

Financial Disclosure: The authors declared that this study has received no financial support.

\section{References}

1. Nelson CP, Dunn R, Wan J, Wei JT. The increasing incidence of newborn circumcision: data from the nationwide inpatient sample. J Urol 2005;173:978-81 . [CrossRef]

2. Hutcheson JP. Male neonatal circumcision: indications, controversies and complications. Urol Clin North Am 2004;31:461-7. [CrossRef]

3. Krill AJ, Palmer LS, Palmer JS. Complications of circumcision. ScientificWorldJournal 2011;11:2458-68. [CrossRef]

4. American Academy of Pediatrics Task Force on Circumcision Male Circumcision. Pediatrics 2012;130:e756-85.

5. Kidger EA, Haider N, Qazi A. Acquired phimosis after plastibell circumcision: A preventable consequence. Ann R Coll Surg Engl 2012;94:e186-8. 